\title{
Potencial agronómico de 18 líneas de fréjol F6 en Ecuador
}

\author{
Agronomic potential of 18 F6 bean lines in Ecuador \\ Felipe Rafael Garcés-Fiallos ${ }^{1}$, Ismael Modesto Olmedo-Zamora ${ }^{1}$, \\ Rafael Edmundo Garcés-Estrella ${ }^{1}$,Teofilo Gorki Díaz-Coronel ${ }^{1}$
}

\begin{abstract}
RESUMEN
El objetivo de esta investigación fue evaluar el potencial agronómico de 18 líneas F6 de fréjol durante la época seca del 2010 y 2011, en la cuenca alta del río Guayas. Se utilizaron 18 líneas promisorias F6 del cruzamiento $\mathrm{Cf}_{6}$ y como testigo la variedad comercial INIAP-473 (todas de hábito de crecimiento determinado tipo Ia). Se empleó al diseño experimental de bloques completos al azar con 19 tratamientos y 3 repeticiones. Se cuantificó el número de plantas emergidas, días a floración, color de flor, altura de planta e inserción de vaina, intensidad del complejo de enfermedades foliares, y por separado de la roya (Uromyces apendiculatus Pers.:Pers.), mustia hilachosa [Rhizoctonia solani (Kuhn)] y virosis [Bean common mosaic virus (BCMV)], así como el número de vainas por planta, peso de campo y rendimiento de granos. Para la comparación entre las medias de los tratamientos se empleó la prueba de Tukey $(\mathrm{p}<0,05)$, y para la comparación entre los años se utilizó la prueba T Student $(\mathrm{p}<0,05)$. Las líneas promisorias $\mathrm{Cf}_{6}$ 0-0-5-2, $\mathrm{Cf}_{6}$ 0-0-7-2 y Cf 6 0-0-7-7 resultaron agronómica, sanitaria y productivamente superiores.
\end{abstract}

Palabras clave: Phaseolus vulgaris L., agronomía, roya, mustia hilachosa, producción.

\section{ABSTRACT}

The aim of this research was to evaluate the potential agronomic of the 18 lines F6 of bean during the years 2010 and 2011 , in the Guayas river basin. Commercial variety INIAP-473 and 18 lines promising F6 of the crossbreeding Cf6 (all of habit growth determinate type Ia) were used. Randomized complete block design we used with 19 treatments and 3 replications. We quantified the number of emerged plants, days to flowering, flower color, plant height and inserting of pod, intensity of complex of foliar diseases, and separately the rust (Uromyces apendiculatus Pers.:Pers.), web blight [Rhizoctonia solani (Kuhn)] and viruses [Bean common mosaic virus $(B C M V)]$, and the number of pod per plant, fresh grain weight and grain yield. For comparison between treatment means was used Tukey's test $(p<0,05)$, and for comparison between years we used the Student's $t$-test $(p<0,05)$. Cf6 0-0-5-2, Cf6 0-0-7-2 y Cf6 0-0-7-7 promising lines were betters agronomic, sanitary and productively.

Key words: Phaseolus vulgaris L., agronomy, rust, web blight, production.

\section{Introducción}

El fréjol (Phaselous vulgaris L.) es la leguminosa más cultivada y consumida en Ecuador, sea como grano seco o vaina verde (con alto contenido de humedad cosechado antes de la madurez fisiológica) (Ernest et al., 2008). La preferencia por el color de los granos varía según la provincia, siendo apetecidos en Los Ríos los granos de color rojo, en Guayas los de color blanco, bayo, rojo y canario, y en El Oro los de color amarillo (Buestán, 1989).

La superficie promedio cosechada en el país en los cinco últimos años fue de 22.186 ha, correspondientes a 3.410 ha para fréjol arbustivo (hábito de crecimiento determinado) y 18.776 ha para voluble (hábito de crecimiento indeterminado). En el mismo período, el rendimiento promedio para fréjol seco fue de $350 \mathrm{~kg} \mathrm{ha}^{-1}$ y para vaina verde de $1.340 \mathrm{~kg} \mathrm{ha}^{-1}$ (INEC, 1994).

El cultivo de esta leguminosa lo desarrollan pequeños agricultores, y siendo la producción orientada al autoconsumo, abasteciendo paralelamente el mercado interno. En el litoral ecuatoriano se siembra esta leguminosa preferiblemente en la época de verano, con variedades de color claro: amarillo (canario), blanco (caballero) y rojo, aunque en menor cantidad las de color negro, siendo influenciada por la región y gusto del consumidor.

1 Universidad Técnica Estatal de Quevedo. Facultad de Ciencias Agrarias. Km. 1 1/5 vía Santo Domingo de los Tsáchilas, Quevedo, Los Ríos, Ecuador. Casilla postal: 73.

Garcés Fiallos, F.R.: Facultad de Ciencias Agrarias.

Olmedo-Zamora, I.M. \& Díaz-Coronel, T.G.: Facultad de Ciencias Pecuarias.

Garcés-Estrella, R.E.: Facultad de Ciencias Ambientales.

* Autor por correspondencia: rgarces@uteq.edu.ec 
Uno de los factores bióticos que limitan la producción del fréjol en este lugar del país son las enfermedades, teniendo entre ellas a la roya (Uromyces apendiculatus Pers.:Pers.), mustia hilachosa [Rhizoctonia solani (Kuhn)] y virosis, así como pudriciones radiculares [Fusarium spp., $R$. solani, Macrophomina phaseolina (Tassi) Goid. y Sclerotium rolfsii Sacc.] (Garcés-Fiallos, 2011; 2013; Garcés-Fiallos \& Gamarra-Yánez, 2014; GarcésFiallos et al., 2012). La mustia hilachosa es la más perjudicial para este cultivo, ya que puede causar daños en el rendimiento y pérdidas al productor, el que puede dejar de percibir una tonelada cuando la severidad alcanza magnitudes de 7,79\% (GarcésFiallos, 2011), una cifra significativa al considerar el bajo rendimiento nacional. Considerada la más destructiva del fréjol por la defoliación rápida y drástica que causa (Rodríguez et al., 1999), esta enfermedad también afecta negativamente el número de nudos, vainas y cantidad de granos por planta (Garcés-Fiallos et al., 2013). Aun no se ha identificado una línea de fréjol con alto nivel de resistencia a la mustia hilachosa (Beaver et al., 2002).

Los actuales genotipos utilizados en el país y específicamente en la cuenca alta del río Guayas no compensan la inversión realizada por los agricultores (Garcés-Fiallos et al., 2012). Ante este panorama, la Universidad Técnica Estatal de Quevedo (UTEQ) desarrolló un programa de mejoramiento de esta especie, realizando estudios agronómicos, cuantificaciones fitopatométricas de las diferentes enfermedades, así como evaluaciones productivas de germoplasma, con la finalidad de ofrecer una variedad con excelentes características agronómicas, sanitarias y productivas para la cuenca alta del río Guayas.

El objetivo de esta investigación fue evaluar el potencial agronómico de 18 líneas F6 de fréjol durante la época seca de 2010 y 2011 en la cuenca alta del río Guayas.

\section{Materiales y Métodos}

La investigación se realizó durante la época de verano, en 2010 (septiembre-diciembre) y 2011 (julio-octubre), en la Finca Experimental La María, de la Universidad Técnica Estatal de Quevedo (79 30 ' 08 " de longitud Oeste y $01^{\circ} 00$ ' 35 " latitud Sur, $73 \mathrm{msnm}$ ). Caracterizado como bosque húmedotropical (bh-T), con topografía plana, suelo de textura francoarcilloso, tipo inceptisol y pH 5,7.
Se utilizaron 18 líneas promisorias F6 de fréjol, obtenidas del cruzamiento $\mathrm{Cf}_{6}$ (variedad INIAP473 y la línea promisoria EVG-6-248, ambas de hábito de crecimiento determinado tipo Ia) en la UTEQ por el método genealógico $\left(\mathrm{Cf}_{6}\right.$ 0-0-1-9, $\mathrm{Cf}_{6} 0-0-1-12, \mathrm{Cf}_{6} 0-0-3-1, \mathrm{Cf}_{6} 0-0-3-7, \mathrm{Cf}_{6} 0-0-4-8$, $\mathrm{Cf}_{6} 0-0-4-9, \mathrm{Cf}_{6} 0-0-4-13, \mathrm{Cf}_{6} 0-0-5-2, \mathrm{Cf}_{6} 0-0-5-4$, $\mathrm{Cf}_{6} 0-0-5-5, \mathrm{Cf}_{6} 0-0-5-7, \mathrm{Cf}_{6} 0-0-7-1, \mathrm{Cf}_{6} 0-0-7-2$, $\mathrm{Cf}_{6} 0-0-7-3, \mathrm{Cf}_{6} 0-0-7-6, \mathrm{Cf}_{6} 0-0-7-7, \mathrm{Cf}_{6} 0-0-7-8$ y $\left.\mathrm{Cf}_{6} 0-0-7-9\right)$, utilizando como testigo la variedad comercial INIAP-473.

\section{Manejo experimental}

Antes de la siembra, el suelo se preparó con tres pases de rastra, limpiando manualmente restos de arvenses. Antes de la siembra se irrigó por dos horas. Se sembró el 18 de septiembre de 2010, y el 16 de julio de 2011, de forma convencional, utilizando un espeque, a una profundidad de $3 \mathrm{~cm}$, depositando una semilla por agujero. La distancia entre hileras (cuatro hileras de $6 \mathrm{~m}$ cada una) fue de $0,50 \mathrm{~m}$ y de $0,20 \mathrm{~cm}$ entre plantas, conformando parcelas de $9 \mathrm{~m}^{2}$ cada una, y un área total experimental de $924 \mathrm{~m}^{2}$. La semilla fue tratada con el fungicida Carbendazim en dosis de $3 \mathrm{~cm}^{3} \mathrm{~kg}^{-1}$ de semilla. Para prevenir el ataque de insectos plagas se aplicó lambdacihalotrina, clorpirifos e imidacloprid con dosis de 0,$2 ; 2,0$ y $0,5 \mathrm{~L} \mathrm{ha}^{-1}$, respectivamente. No se aplicó fungicida en la parte aérea. Se fertilizó en función del análisis de suelo (Tabla 1), utilizando una fuente de P (46\%), otra de Mg (18\%) y una última de B (34\%), a razón de 100, 50 y $10 \mathrm{~kg} \mathrm{ha}^{-1}$, respectivamente, 16 y 30 días después de la siembra (DDS). Se irrigó en función de la necesidad hídrica del cultivo. Los experimentos se cosecharon el 2 de diciembre de 2010 (75 DDS) y el 4 de octubre de 2011 (80 DDS), en el estado fenológico R9 (maduración fisiológica-vainas totalmente secas) (Hall, 1991).

Los datos meteorológicos se obtuvieron en la División de Meteorología, Departamento de Sinóptica del Instituto Nacional Autónomo de Investigaciones Agropecuarias (INIAP), Quevedo (Tabla 2).

\section{Variables agronómicas}

Número de plantas emergidas: se contabilizó el número de plantas emergidas en la parcela útil (dos hileras centrales) de cada uno de los tratamientos, 16 DDS. 
Tabla 1. Análisis de suelo realizado durante el 2010. Campo Experimental La María, Quevedo. 2011.

\begin{tabular}{|c|c|c|c|c|c|c|c|c|c|c|c|c|c|c|c|c|}
\hline \multirow{2}{*}{$\begin{array}{l}\text { Parámetros } \\
\text { analizados }\end{array}$} & \multirow[b]{2}{*}{$\mathrm{Ph}$} & \multicolumn{2}{|c|}{ ppm } & \multicolumn{3}{|c|}{ meq $100 \mathrm{~mL}^{-1}$} & \multicolumn{6}{|c|}{ ppm } & \multirow{2}{*}{$\begin{array}{c}\text { Materia } \\
\text { orgánica } \\
(\%)\end{array}$} & \multicolumn{3}{|c|}{ Textura (\%) } \\
\hline & & $\mathrm{N}$ & $\mathrm{P}$ & $\mathrm{K}$ & $\mathrm{Ca}$ & $\mathrm{Mg}$ & $\mathrm{S}$ & $\mathrm{Zn}$ & $\mathrm{Cu}$ & $\mathrm{Fe}$ & $\mathrm{Mn}$ & B & & Arena & Limo & Arcilla \\
\hline Cantidad & 5,7 & 49 & 16 & 0,97 & 11 & 1,7 & 42 & 3,6 & 8,2 & 199 & 11,1 & 0,16 & 3,3 & 36 & 42 & 22 \\
\hline Interpretación & $\mathrm{MeAc}^{1}$ & $\mathrm{~A}^{2}$ & $\mathrm{M}^{3}$ & A & A & M & A & M & A & A & M & $\mathrm{B}^{4}$ & M & & Franco & \\
\hline
\end{tabular}

${ }^{1}$ MeAc: Medio ácido. ${ }^{2}$ A: Alto. ${ }^{3}$ M: Medio. ${ }^{4}$ B: Bajo.

Tabla 2. Condiciones climáticas registradas durante cuatro meses, para cada uno de los experimentos correspondientes a 2010 y 2011. Campo Experimental La María, UTEQ, Quevedo.

\begin{tabular}{lcccccccccc}
\hline \multirow{2}{*}{ Condiciones climáticas $^{1}$} & 2010 & 2011 & 2010 & 2011 & 2010 & 2011 & 2010 & 2011 & \multicolumn{2}{c}{ Días del cultivo $^{3}$} \\
\cline { 2 - 9 } & Sep. & Jul. & Oct. & Ago. & Nov. & Sep. & Dic. & Oct. & 2010 & 2011 \\
\hline Temperatura promedio $\left({ }^{\circ} \mathrm{C}\right)$ & 24,64 & 24,43 & 21,85 & 23,33 & 23,52 & 24,18 & 23,85 & 24,85 & 23,80 & 23,90 \\
Humedad relativa promedio $(\%)$ & 84,17 & 87,69 & 83,00 & 87,32 & 84,43 & 84,23 & 82,00 & 82,00 & 83,40 & 86,00 \\
Heliofanía total (horas luz) & 17,40 & 37,00 & 53,30 & 37,30 & 33,70 & 84,30 & 1,50 & 11,70 & 115,40 & 170,30 \\
Precipitación pluvial total (mm) & 5,60 & 11,40 & 0,80 & 1,10 & 21,80 & 4,20 & 0,00 & 0,30 & 28,50 & 17,00 \\
\hline
\end{tabular}

${ }^{1}$ Fuente: División de Meteorología, Departamento de Sinóptica del Instituto Nacional Autónomo de Investigaciones AgropecuariasINIAP, Quevedo, Ecuador.

${ }^{2}$ Meses para cada uno de los experimentos, en función de cada año de investigación (Jul.; julio; Ago.: agosto; Sep.; septiembre; Oct.; octubre; Nov.: noviembre; Dic.: diciembre).

${ }^{3}$ Días transcurridos desde la fecha de siembra hasta la cosecha de todos los materiales establecidos en el campo.

Días a floración: se registró el número de días transcurridos desde la fecha de siembra hasta el $50 \%$ más uno de las plantas de cada parcela cuando presentaron flores abiertas, describiendo también el color de flor de cada genotipo.

Altura de planta e inserción de vaina: se registraron en el estado fenológico reproductivo R8 (inicio del llenado de vainas; comienzo de senescencia) (Hall, 1994), en 10 plantas tomadas al azar en cada parcela útil, midiendo la distancia $(\mathrm{cm})$ entre el suelo y el ápice del tallo, y entre el suelo y la inserción de la primera vaina.

\section{Variables sanitarias}

El Área Abajo la Curva de Progreso de la Enfermedad en Plantas Marcadas (AACPEPM) define la severidad (porcentaje) de enfermedades foliares en plantas marcadas: para la evaluación visual de la severidad en cada material vegetal se marcaron cuatro plantas por tratamiento (dos en cada hilera de la parcela útil). Se consideró como planta enferma aquella que presentaba necrosis o muerte del tejido foliar debido al ataque del complejo de enfermedades foliares (Rhizoctonia solani y
Uromyces apendiculatus). Esta evaluación se hizo durante seis semanas, con intervalos de siete días, totalizando seis evaluaciones.

Severidad de la roya: se realizó en los estados fenológicos reproductivos R7 (primera vaina visible con la corola de la flor colgada o desprendida) y R8. Se cuantificó el número de uredias $\mathrm{cm}^{2}$ en folíolos centrales de cada estrato (inferior, medio y superior), de cuatro plantas escogidas al azar en las dos hileras laterales, sumando 12 folíolos centrales. En estos folíolos también se estimó la severidad de la roya, utilizando la escala diagramática de Godoy et al. (1997).

Incidencia (porcentaje) de virosis: se cuantificó en el estado fenológico R7, contabilizando cada una de las plantas de la parcela útil, mediante una evaluación visual de los síntomas ocasionados por virus (Bianchini et al., 2005; Hall, 1994; GarcésFiallos, 2010).

Severidad de la mustia hilachosa: se realizó en los estados fenológicos reproductivos R7 y R8. En cada uno de los folíolos centrales donde se analizó la roya se cuantificó el número de lesiones folíolo ${ }^{-1}$ y el porcentaje (otorgándole un valor en función del área necrosada). 


\section{Variables productivas}

Número de vainas por planta: en 10 plantas tomadas al azar en cada parcela útil, se cuantificó el número de vainas por planta.

Peso de campo: después de la cosecha se trillaron manualmente todas las plantas del área útil de cada parcela experimental. Se pesó el grano resultante en una balanza electrónica, y su resultado se expresó en $\mathrm{kg}$.

Rendimiento de granos por hectárea: Se obtuvo con los promedios de la variable anterior, utilizando el tamaño del área colectada, transformándose para kg ha $^{-1}$ y ajustados al $13 \%$ de humedad.

\section{Diseño y análisis experimental}

Se empleó el diseño de bloques completos al azar con 19 tratamientos y 3 repeticiones. Se realizaron los testes de Bartlett y de Shapiro-Wilks, para verificar la existencia de homocedasticidad (variancias) y normalidad (residuos), respectivamente. Para la comparación entre las medias de los tratamientos se empleó la prueba de Tukey al 5\% de probabilidad del error. Para la comparación entre las medias de cada uno de los años, se utilizó la prueba T Student al 5\% de probabilidad del error. Para la comparación general entre los individuos se obtuvo el promedio de todas las variables sanitarias, y las agronómicas y productivas, midiendo por medio del coeficiente de similaridad, mediante el análisis de conglomerados, utilizando el método de Ward, obteniendo su respectivo dendograma. Se emplearon los programas ASSISTAT versión 7,5 beta 2012 (Silva \& Azevedo, 2002) y MINITAB (Ryan et al., 2005).

\section{Resultados y Discusión}

\section{Variables agronómicas}

Solamente la variable emergencia de plántulas mostró diferencia estadística entre los genotipos durante el 2011 (Tabla 3). El porcentaje se ubicó entre $82,8\left(\mathrm{Cf}_{6} 0-0-1-12\right.$ y Cf $\left.60-0-3-7\right)$ y $96,1 \%$ $\left(\mathrm{Cf}_{6}\right.$ 0-0-7-2) durante el 2010. Durante el 2011, los materiales $\mathrm{Cf}_{6}$ 0-0-4-8, $\mathrm{Cf}_{6}$ 0-0-4-9 (93,3\%),

Tabla 3. Emergencia de plántulas (\%), días a floración, altura de planta $(\mathrm{cm})$ y altura de inserción de vaina $(\mathrm{cm})$ de líneas promisorias $\mathrm{F}_{6}$ de fréjol obtenidas en la UTEQ y una variedad comercial, en la época seca de los años 2010 y 2011. Campo Experimental La María, Quevedo. 2011.

\begin{tabular}{|c|c|c|c|c|c|c|c|c|}
\hline \multirow[t]{2}{*}{ Tratamientos } & \multicolumn{2}{|c|}{$\begin{array}{l}\text { Emergencia de } \\
\text { plántulas (\%) }\end{array}$} & \multicolumn{2}{|c|}{ Días floración } & \multicolumn{2}{|c|}{$\begin{array}{l}\text { Altura de planta } \\
\qquad(\mathrm{cm})\end{array}$} & \multicolumn{2}{|c|}{$\begin{array}{c}\text { Altura de inserción } \\
\text { de vaina }(\mathrm{cm})\end{array}$} \\
\hline & 2010 & 2011 & 2010 & 2011 & 2010 & 2011 & 2010 & 2011 \\
\hline $\mathrm{Cf}_{6} 0-0-1-9$ & $86,6 \mathrm{~ns}$. & $88,3 \mathrm{ab}^{1}$ & 33 ns. & 33 ns. & $46,0 \mathrm{~ns}$. & $46,7 \mathrm{a}$ & 19,9 ns. & $18,6 \mathrm{~ns}$ \\
\hline $\mathrm{Cf}_{6} 0-0-1-12$ & 82,8 & $89,4 \mathrm{ab}$ & 31 & 31 & 43,2 & $40,7 \mathrm{~b}$ & 19,8 & 19,0 \\
\hline $\mathrm{Cf}_{6} 0-0-3-1$ & 89,4 & 98,9 a & 32 & 32 & 45,7 & $44,0 \mathrm{ab}$ & 20,2 & 20,7 \\
\hline $\mathrm{Cf}_{6} 0-0-3-7$ & 82,8 & $90,6 \mathrm{ab}$ & 32 & 32 & 42,1 & $41,5 \mathrm{ab}$ & 18,6 & 19,7 \\
\hline $\mathrm{Cf}_{6} 0-0-4-8$ & 83,3 & 93,3 a & 31 & 30 & 45,5 & $44,8 \mathrm{ab}$ & 20,2 & 20,9 \\
\hline $\mathrm{Cf}_{6}^{0} 0-0-4-9$ & 94,4 & 93,3 a & 31 & 31 & 42,6 & $44,0 \mathrm{ab}$ & 19,0 & 18,7 \\
\hline $\mathrm{Cf}_{6} 0-0-4-13$ & 92,2 & 93,9 a & 32 & 32 & 41,7 & $43,1 \mathrm{ab}$ & 20,4 & 19,3 \\
\hline $\mathrm{Cf}_{6} 0-0-5-2$ & 94,4 & $91,1 \mathrm{ab}$ & 32 & 32 & 40,0 & $41,0 \mathrm{ab}$ & 18,3 & 20,3 \\
\hline $\mathrm{Cf}_{6} 0-0-5-4$ & 86,1 & $92,2 \mathrm{ab}$ & 31 & 31 & 46,4 & $45,8 \mathrm{ab}$ & 20,6 & 20,7 \\
\hline $\mathrm{Cf}_{6} 0-0-5-5$ & 93,9 & $90,0 \mathrm{ab}$ & 31 & 31 & 42,2 & $44,1 \mathrm{ab}$ & 19,9 & 19,1 \\
\hline $\mathrm{Cf}_{6} 0-0-5-7$ & 92,2 & $86,7 \mathrm{ab}$ & 31 & 32 & 43,5 & $44,4 \mathrm{ab}$ & 20,1 & 19,3 \\
\hline $\mathrm{Cf}_{6} 0-0-7-1$ & 94,4 & $88,9 \mathrm{ab}$ & 32 & 33 & 41,5 & $45,1 \mathrm{ab}$ & 19,5 & 19,9 \\
\hline $\mathrm{Cf}_{6}^{0} 0-0-7-2$ & 96,1 & $92,7 \mathrm{ab}$ & 32 & 32 & 43,7 & $45,4 \mathrm{ab}$ & 19,0 & 19,7 \\
\hline $\mathrm{Cf}_{6} 0-0-7-3$ & 84,4 & $87,2 \mathrm{ab}$ & 33 & 31 & 45,8 & $46,4 a b$ & 19,9 & 20,6 \\
\hline $\mathrm{Cf}_{6} 0-0-7-6$ & 92,7 & $89,2 \mathrm{ab}$ & 32 & 32 & 43,5 & $43,6 \mathrm{ab}$ & 19,6 & 20,0 \\
\hline $\mathrm{Cf}_{6} 0-0-7-7$ & 93,3 & $91,7 \mathrm{ab}$ & 31 & 32 & 47,0 & $44,5 \mathrm{ab}$ & 19,9 & 20,9 \\
\hline $\mathrm{Cf}_{6} 0-0-7-8$ & 91,1 & $89,4 \mathrm{ab}$ & 32 & 32 & 45,1 & $42,5 \mathrm{ab}$ & 18,1 & 18,6 \\
\hline $\mathrm{Cf}_{6} 0-0-7-9$ & 91,1 & $90,0 \mathrm{ab}$ & 32 & 33 & 43,2 & $43,6 \mathrm{ab}$ & 19,1 & 20,0 \\
\hline INIAP-473 & 87,2 & $80,6 \mathrm{~b}$ & 31 & 33 & 41,6 & $42,4 \mathrm{ab}$ & 18,8 & 18,4 \\
\hline Promedio & 89,9 ns. & 90,4 & 32 ns. & 32 & 43,7 ns. & 43,9 & 19,5 ns. & 19,7 \\
\hline $\mathrm{CV}(\%)$ & 8,44 & 4,48 & 2,02 & 4,50 & 6,85 & 4,34 & 7,41 & 6,64 \\
\hline
\end{tabular}

${ }^{1}$ Medias seguidas por la misma letra en la columna (genotipos) no difieren estadísticamente por el teste de Tukey al $5 \%$ de probabilidad, entre tanto en la fila (promedio de los genotipos) no difieren estadísticamente por el teste de $\mathrm{T}$ al $5 \%$ de probabilidad. 
$\mathrm{Cf}_{6}$ 0-0-4-13 (93,9\%) y Cf 6 0-0-3-1 (98,9\%), fueron estadísticamente superiores a los demás, resultando con el menor porcentaje de emergencia la variedad INIAP-473 (80,6\%) (Tabla 3). A pesar de la diferencia encontrada entre los genotipos estudiados, esta se puede considerar aceptable. En un experimento realizado en condiciones controladas evaluando la germinación de semillas de 26 genotipos de fréjol criollo (semillas obtenidas de un experimento a campo), utilizando la metodología de papel germitest, se encontró una germinación entre 37 y 100\% (Coelho et al., 2010). El tamaño de la semilla dentro de cada especie vegetal es un factor que puede afectar la germinación y emergencia de plántulas de fréjol, pues semillas de menor tamaño, por la cantidad reducida de reservas que puedan contener, tienen germinación reducida (Celis-Velázquez et al., 2010), no siendo el caso de estos materiales, ya que todos poseen tamaño similar (grandes, rojizos entre ovalados y arriñonados) e inclusive una emergencia superior al $80 \%$ durante los dos años.

Los días a floración se ubicaron entre 31 y 33 durante 2010, mientras que entre 30 y 33 días durante 2011, no mostrando diferencias significativas. En su mayoría la divergencia fue de dos días entre los genotipos evaluados, exceptuando la línea promisoria $\mathrm{Cf}_{6}$ 0-0-4-8 que alcanzó la floración a los 30 días durante el 2011, no observándose diferencia estadística ni numérica (32 días) entre los años evaluados (Tabla 3). Estos promedios son similares a los obtenidos (entre 31 y 33 DDS) por Garcés-Fiallos et al. (2012) durante el 2010, en líneas promisorias F5 y variedades. Estos genotipos se enmarcan como precoces según Vargas-Vásquez et al. (2008). Todos los materiales evaluados presentaron color de flor blanca, mostrando uniformidad en esta variable.

La altura de planta e inserción de vaina mostró diferencia estadística solamente en la primera variable en el 2011. No existió diferencia significativa entre los años para las dos variables. Para altura de planta el promedio fluctuó entre 40 $\left(\mathrm{Cf}_{6} 0-0-5-2\right)$ y $47 \mathrm{~cm}\left(\mathrm{Cf}_{6} 0-0-7-7\right)$, y entre 40,7 $\left(\mathrm{Cf}_{6} 0-0-1-12\right)$ y $46,7 \mathrm{~cm}\left(\mathrm{Cf}_{6} 0-0-1-9\right)$, en 2010 y 2011, respectivamente (Tabla 3). Para la altura de inserción de vaina los valores se ubicaron entre 18,1 $\left(\mathrm{Cf}_{6} 0-0-7-8\right)$ y $20,6 \mathrm{~cm}\left(\mathrm{Cf}_{6} 0-0-5-4\right)$, y entre 18,4 (INIAP-473) y $20,9 \mathrm{~cm}\left(\mathrm{Cf}_{6} 0-0-4-8\right.$ y $\left.\mathrm{Cf}_{6} 0-0-7-7\right)$ en 2010 y 2011, respectivamente (Tabla 3). Estos valores son similares a los encontrados por GarcésFiallos et al. (2012), para altura de planta (38,4 y $47,7 \mathrm{~cm})$ e inserción de vaina $(15,5$ y 19,9 cm). La uniformidad presentada en estos genotipos, se debió al hábito de crecimiento y al determinado tipo de Ia, ya que materiales de crecimiento indeterminado pueden alcanzar alturas de planta entre 1,47 y 2,79 $\mathrm{m}$, y de inserción de vaina entre 5,38 y 13,10 cm (Alves-Francelino et al., 2011). La siembra de estos materiales en esta zona del Ecuador se debe a que no son propensos al volcamiento, y al fácil manejo durante el establecimiento en el campo y la cosecha (Garcés-Fiallos et al., 2012).

\section{Variables sanitarias}

Para el AACPEPM de la severidad (\%) de enfermedades foliares, durante el 2010 los valores estuvieron entre $90\left(\mathrm{Cf}_{6} 0-0-7-3\right)$ y $252,3\left(\mathrm{Cf}_{6}\right.$ 0-0-7-6), mientras que durante el 2011 se ubicaron entre 171,7 ( $\left.\mathrm{Cf}_{6} 0-0-3-1\right)$ y 298,7 unidades $\left(\mathrm{Cf}_{6}\right.$ 0-0-7-3) (Tabla 4). A pesar de haber obtenido un coeficiente de variación bajo $(16,43 \%)$, no presentaron diferencia estadística, debido a que el factor de variación Bloques en el ANOVA mostró variación estadística entre ellos $(0,01)$ (Tabla 4). Estos valores muestran ser inferiores a los obtenidos por Nechet y Halfeld-Vieira (2007), quienes evaluando genotipos de fréjol chino (Vigna unguiculata) a nivel de campo, estimando la severidad de la mustia hilachosa, observaron valores de AACPE entre 335 (IT 87B719) y 668 unidades (Pitiúba), para materiales de comportamiento erecto, y entre 101 (Canapuzinho) a 145 unidades (Tracuateua) para materiales de comportamiento rastrero, difiriendo de la presente investigación. Sin embargo, Garcés-Fiallos (2012) obtuvo valores entre 47,5 y 151,2 unidades, en su mayoría valores menores a los expuestos aquí, debiéndose dichas diferencias a la fitopatometría utilizada por el autor (área foliar necrosada por parcela). Dicho autor también relata que la variedad INIAP-473 se comportó como intermediario en comparación con los demás materiales evaluados.

Se encontró una significativa cantidad de enfermedades foliares durante el 2010 (250,7 unidades) en comparación al $2011(223,6)$, debido posiblemente a la época de siembra de 2010 (septiembre), ocurriendo una epidemia al haber mayor potencial de inóculo proveniente de otros cultivos de fréjol.

Para el número de uredias $\mathrm{cm}^{-2}$ de la roya se encontró diferencia estadística solamente en los estados fenológicos R7 en 2011 y R8 en 2010. En el estado fenológico R7 del 2011, los genotipos 
Tabla 4. Área Abajo la Curva de Progreso de la Enfermedad en Plantas Marcadas (AACPEPM) de la severidad (\%) de enfermedades foliares, así como el número de uredias $\mathrm{cm}^{-2}$ de la roya (Uromyces apendiculatus) en los estados fenológicos R7 (primera vaina visible con la corola de la flor colgada o desprendida) y R8 (inicio del llenado de vainas; comenzando la senescencia) y la incidencia de virosis (\%) en el estado fenológico R7 en líneas promisorias $\mathrm{F}_{6}$ de fréjol obtenidas en la UTEQ y una variedad comercial, durante la época seca de los años 2010 y 2011. Campo Experimental La María, Quevedo. 2011.

\begin{tabular}{|c|c|c|c|c|c|c|c|c|}
\hline \multirow{3}{*}{ Tratamientos } & \multirow{2}{*}{\multicolumn{2}{|c|}{ AАCPEPM }} & \multicolumn{4}{|c|}{ Roya (número de uredias $\mathrm{cm}^{-2}$ ) } & \multirow{2}{*}{\multicolumn{2}{|c|}{ Virosis (\%) }} \\
\hline & & & \multicolumn{2}{|c|}{ R7 } & \multicolumn{2}{|c|}{$\mathrm{R} 8$} & & \\
\hline & 2010 & 2011 & 2010 & 2011 & 2010 & 2011 & 2010 & 2011 \\
\hline $\mathrm{Cf}_{6} 0-0-1-9$ & $160,0 \mathrm{ab}$ & $231,7 \mathrm{~ns}$. & $1,5 \mathrm{~ns}$. & $2,9 \mathrm{ab}$ & $7,1 \mathrm{ab}$ & $6,3 \mathrm{~ns}$. & $6,9 \mathrm{~ns}$. & $1,7 \mathrm{~ns}$. \\
\hline $\mathrm{Cf}_{6}^{0} 0-0-1-12$ & $189,3 \mathrm{ab}$ & 292,0 & 1,4 & $1,4 \mathrm{abcd}$ & $5,2 \mathrm{~b}$ & 6,3 & 5,7 & 3,0 \\
\hline $\mathrm{Cf}_{6} 0-0-3-1$ & $200,3 \mathrm{ab}$ & 171,7 & 2,9 & $2,2 \mathrm{abcd}$ & $5,1 \mathrm{~b}$ & 3,3 & 4,0 & 3,3 \\
\hline $\mathrm{Cf}_{6} 0-0-3-7$ & $213,3 \mathrm{ab}$ & 174,7 & 0,8 & $0,4 \mathrm{~d}$ & $8,5 \mathrm{ab}$ & 5,1 & 4,6 & 6,7 \\
\hline $\mathrm{Cf}_{6} 0-0-4-8$ & $198,0 \mathrm{ab}$ & 197,7 & 1,4 & $2,7 \mathrm{abc}$ & $7,6 \mathrm{ab}$ & 4,5 & 2,8 & 2,3 \\
\hline $\mathrm{Cf}_{6}^{0} 0-0-4-9$ & $129,7 \mathrm{ab}$ & 186,0 & 4,0 & $1,5 \mathrm{abcd}$ & $4,8 \mathrm{~b}$ & 5,9 & 1,3 & 7,0 \\
\hline $\mathrm{Cf}_{6}^{0} 0-0-4-13$ & $169,7 \mathrm{ab}$ & 270,7 & 2,5 & 1,2 abcd & $6,4 \mathrm{ab}$ & 7,6 & 5,4 & 4,7 \\
\hline $\mathrm{Cf}_{6}^{0} 0-0-5-2$ & $133,3 \mathrm{ab}$ & 232,7 & 1,1 & $3,2 \mathrm{a}$ & $7,7 \mathrm{ab}$ & 7,2 & 10,1 & 3,0 \\
\hline $\mathrm{Cf}_{6}^{0} 0-0-5-4$ & $216,3 \mathrm{ab}$ & 206,0 & 4,0 & $2,1 \mathrm{abcd}$ & $12,5 \mathrm{a}$ & 6,3 & 1,7 & 5,7 \\
\hline $\mathrm{Cf}_{6}^{6} 0-0-5-5$ & $190,7 \mathrm{ab}$ & 200,7 & 2,1 & $1,4 \mathrm{abcd}$ & $4,9 \mathrm{~b}$ & 3,8 & 4,2 & 5,7 \\
\hline $\mathrm{Cf}_{6} 0-0-5-7$ & $158,0 \mathrm{ab}$ & 184,7 & 1,2 & $0,9 \mathrm{bcd}$ & $6,2 \mathrm{ab}$ & 5,3 & 1,5 & 6,3 \\
\hline $\mathrm{Cf}_{6} 0-0-7-1$ & $174,7 \mathrm{ab}$ & 231,3 & 1,4 & $0,9 \mathrm{bcd}$ & $7,8 \mathrm{ab}$ & 7,1 & 8,7 & 2,7 \\
\hline $\mathrm{Cf}_{6}^{0} 0-0-7-2$ & $157,3 \mathrm{ab}$ & 203,7 & 1,1 & $0,9 \mathrm{bcd}$ & $7,8 \mathrm{ab}$ & 6,9 & 4,5 & 3,3 \\
\hline $\mathrm{Cf}_{6}^{0} 0-0-7-3$ & $90,0 \mathrm{~b}$ & 298,7 & 1,4 & $0,7 \mathrm{~cd}$ & $7,1 \mathrm{ab}$ & 7,2 & 3,5 & 2,3 \\
\hline $\mathrm{Cf}_{6}^{6} 0-0-7-6$ & $235,7 \mathrm{a}$ & 257,7 & 0,9 & 1,4 abcd & $5,4 \mathrm{~b}$ & 6,2 & 4,9 & 6,7 \\
\hline $\mathrm{Cf}_{6}^{0} 0-0-7-7$ & $160,3 \mathrm{ab}$ & 196,0 & 1,4 & $1,0 \mathrm{bcd}$ & $3,2 \mathrm{~b}$ & 4,1 & 0,7 & 3,7 \\
\hline $\mathrm{Cf}_{6}^{6} 0-0-7-8$ & $183,7 \mathrm{ab}$ & 225,3 & 1,1 & $1,1 \mathrm{abcd}$ & $7,1 \mathrm{ab}$ & 3,7 & 1,2 & 7,7 \\
\hline $\mathrm{Cf}_{6} 0-0-7-9$ & 252,3 a & 293,7 & 1,7 & $0,5 \mathrm{~d}$ & $6,8 \mathrm{ab}$ & 5,4 & 5,9 & 4,7 \\
\hline INIAP-473 & $126,3 \mathrm{ab}$ & 193,3 & 1,5 & 1,9 abcd & $7,6 \mathrm{ab}$ & 7,5 & 5,1 & 0,3 \\
\hline Promedio & $250,7 \mathrm{~A}$ & 223,6 B & $1,7 \mathrm{~ns}$. & 1,5 & $6,8 \mathrm{~ns}$. & 5,8 & 4,4 ns. & 4,3 \\
\hline $\mathrm{CV}(\%)$ & 15,32 & 16,43 & 38,99 & 21,72 & 31,20 & 39,12 & 38,24 & 37,78 \\
\hline
\end{tabular}

${ }^{1}$ Medias seguidas por la misma letra en la columna no difieren estadísticamente por el test de Tukey al 5\% de probabilidad, entre tanto en la fila no difieren estadísticamente por el test de $\mathrm{T}$ al $5 \%$ de probabilidad.

$\mathrm{Cf}_{6}$ 0-0-3-7 y Cf 6 0-0-7-9, con 0,4 y 0,5 uredias, obtuvieron la menor cantidad de enfermedad (Tabla 4). Entre tanto, en el estado fenológico R8 del 2010 las líneas con menor severidad fueron $\mathrm{Cf}_{6} 0-0-7-7, \mathrm{Cf}_{6} 0-0-4-9, \mathrm{Cf}_{6} 0-0-5-5, \mathrm{Cf}_{6} 0-0-3-1$ y $\mathrm{Cf}_{6} 0-0-1-12$ con 3,$2 ; 4,8 ; 4,9 ; 5,1$ y 5,2 uredias, respectivamente (Tabla 4). Comportamiento diferenciado entre cultivares también ha sido encontrado en México por López et al. (2003). El número de uredias $\mathrm{cm}^{-2}(0,4 \mathrm{y} 12,5$ uredias) fue inferior al obtenido por Garcés-Fiallos (2013) (0,54 y 41,39 uredias) en condiciones agroclimáticas y de cultivo similares, y por Iriti; Faoro (2003) ( 23,25 y 41,62 uredias) en condiciones controladas, utilizando una suspensión de $10^{5}$ urediosporas $\mathrm{mL}^{-1}$. El comportamiento diferenciado de las líneas promisorias $\mathrm{Cf}_{6}$ 0-0-3-7 y Cf 6 0-0-3-1, que se destacaron por obtener la menor cantidad de uredias $\mathrm{cm}^{-2}$, en los estados R7 y R8, respectivamente, muestran tolerancia a la roya.
La severidad de la roya se ubicó en el $1 \%$ (datos no mostrados), lo que es menor a $4,64 \%$ obtenido por Garcés-Fiallos et al. (2012) en condiciones agroclimáticas y de cultivo similares, utilizando la escala de Godoy et al. (1997).

Existieron diferencias numéricas pero no estadísticas entre los años agrícolas (Tabla 4), en el estado fenológico R7 para el 2010 (1,7 uredias) y 2011 (1,5 uredias), y en R8 para el 2010 (6,8 uredias) y 2011 (5,8 uredias), evidenciándose un ligero aumento de la roya durante el primer año de estudio.

Se encontró el virus del mosaico común [Bean common mosaic virus (BCMV)] descrito en la sierra central (Lépiz et al., 1995) y norte (Ernest et al., 2008), así como en el litoral (Guamán et al., 2003) de Ecuador. No se localizaron diferencias estadísticas para estas variables, observándose una incidencia entre $0,7\left(\mathrm{Cf}_{6} 0-0-7-7\right)$ y $10,1\left(\mathrm{Cf}_{6}\right.$ $0-0-5-2)$, y entre 0,3 (INIAP-473) y 7,7\% ( $\mathrm{Cf}_{6}$ 
0-0-7-8), en los estados fenológicos R7 y R8, respectivamente, y entre 4,3 y 4,4\% para 2010 y 2011, respectivamente (Tabla 4).

Para mustia hilachosa se evidenció diferencia estadística en casi todas las variables evaluadas, exceptuando el número de lesiones folíolo ${ }^{-1}$ en el estado fenológico R8 del 2011 (Tabla 5).

Esta enfermedad en el estado R7 en el 2010 los valores se ubicaron entre $0,4\left(\mathrm{Cf}_{6} 0-0-5-7 \mathrm{y}\right.$ $\left.\mathrm{Cf}_{6} 0-0-7-8\right)$ y 0,8 lesiones $\left(\mathrm{Cf}_{6} 0-0-7-1\right.$ y $\mathrm{Cf}_{6} 0-0-$ 7-7), sin embargo, en el 2011 los promedios se encontraron entre $0,2\left(\mathrm{Cf}_{6} 0-0-7-8\right)$ y 0,9 lesiones (Cf 6 0-0-7-3) (Tabla 5). En el estadio R8 del 2010 las medias estuvieron entre 1,4 (INIAP-473) y 5,2 lesiones $\left(\mathrm{Cf}_{6}\right.$ 0-0-3-7), mientras que para el siguiente año entre 1,2 ( $\mathrm{Cf}_{6}$ 0-0-4-13 e INIAP-473) y 3,3 lesiones ( $\left.\mathrm{Cf}_{6} 0-0-4-9\right)$ (Tabla 5). El mayor valor de 5,2 lesiones encontrado en la línea $\mathrm{Cf}_{6}$ 0-0-3-7 en el estado R8 del 2010, es menor a las 7,8 lesiones $\left(\mathrm{Cf}_{6} 0-0-4-9\right)$ y 10,6 lesiones $\left(\mathrm{Cf}_{4} 0-0-16-6\right)$ obtenidos por Garcés-Fiallos et al.(2013) y GarcésFiallos (2013), respectivamente, en condiciones similares al del presente experimento, confirmando el comportamiento sanitario superior de todas las líneas promisorias, en especial la $\mathrm{Cf}_{6}$ 0-0-7-3 que fue sanitaria y estadísticamente superior durante el 2010 y obtuvo un valor bajo durante el 2011.

Para la severidad (\%) de la mustia hilachosa, en el estado R7 durante el 2010, los valores se ubicaron entre $1,1\left(\mathrm{Cf}_{6} 0-0-7-8\right)$ y $7,8 \%\left(\mathrm{Cf}_{6} 0-0-7-1\right)$, y en el 2011 entre $2,0\left(\mathrm{Cf}_{6} 0-0-7-8\right)$ y $8,3 \%\left(\mathrm{Cf}_{6} 0-0-4-9\right)$ (Tabla 5). Ya en el estado R8 del 2010, los valores fluctuaron entre $3,7\left(\mathrm{Cf}_{6} 0-0-4-8\right)$ y $14,1 \%\left(\mathrm{Cf}_{6}\right.$ 0-0-3-7), y en el siguiente año entre 3,3 ( $\mathrm{Cf}_{6} 0-0$ 4-13) y $15,8 \%\left(\mathrm{Cf}_{6}\right.$ 0-0-4-9) (Tabla 5).

El número de lesiones fue mayor en el 2010 (2,7 lesiones), en relación con el 2011 ( 1,8 lesiones). La mustia hilachosa se presenta en terrenos infectados con períodos prolongados de lluvia, temperatura y humedad relativa promedio de $24^{\circ} \mathrm{C}$ y $80 \%$ (Rodríguez et al., 1999; Nechet \& Halfeld-Vieira, 2007). Ambas condiciones se presentaron durante los años de investigación, por lo que este comportamiento se debió posiblemente a la precipitación de 21,80 mm

Tabla 5. Número de lesiones folíolo ${ }^{-1}$ de severidad (\%) de mustia hilachosa (Rhizoctonia solani) cuantificada en los estados fenológicos R7 (primera vaina visible con la corola de la flor colgada o desprendida) y R8 (inicio del llenado de vainas; comenzando la senescencia), en líneas promisorias $\mathrm{F}_{6}$ de fréjol obtenidas en la UTEQ y una variedad comercial, durante la época seca de 2010 y 2011. Campo Experimental La María, Quevedo. 2011

\begin{tabular}{|c|c|c|c|c|c|c|c|c|}
\hline \multirow{3}{*}{ Tratamientos } & \multicolumn{4}{|c|}{ Número de lesiones por folíolo } & \multicolumn{4}{|c|}{ Severidad $(\%)$} \\
\hline & \multicolumn{2}{|c|}{ R7 } & \multicolumn{2}{|c|}{$\mathrm{R} 8$} & \multicolumn{2}{|c|}{ R7 } & \multicolumn{2}{|c|}{$\mathrm{R} 8$} \\
\hline & 2010 & 2011 & 2010 & 2011 & 2010 & 2011 & 2010 & 2011 \\
\hline $\mathrm{Cf}_{6} 0-0-1-9$ & 0,6 abcd & 0,5 abcd & $1,9 \mathrm{~cd}$ & $1,6 \mathrm{~ns}$. & $4,5 \mathrm{ab}$ & $4,0 \mathrm{ab}$ & $4,7 \mathrm{~cd}$ & $4,5 \mathrm{ab}$ \\
\hline $\mathrm{Cf}_{6} 0-0-1-12$ & 0,6 abcd & $0,5 \mathrm{abcd}$ & $2,3 \mathrm{bcd}$ & 2,1 & $4,5 \mathrm{ab}$ & $4,3 \mathrm{ab}$ & $5,8 \mathrm{~cd}$ & $7,0 \mathrm{ab}$ \\
\hline $\mathrm{Cf}_{6}^{\circ} 0-0-3-1$ & 0,6 abcd & 0,5 abcd & $3,8 \mathrm{abc}$ & 1,8 & $3,3 \mathrm{ab}$ & $3,7 \mathrm{ab}$ & $10,3 \mathrm{abc}$ & $5,0 \mathrm{ab}$ \\
\hline $\mathrm{Cf}_{6} 0-0-3-7$ & 0,6 abcd & 0,4 abcd & $5,2 \mathrm{a}$ & 2,7 & $3,8 \mathrm{ab}$ & $3,7 \mathrm{ab}$ & $14,1 \mathrm{a}$ & $8,3 \mathrm{ab}$ \\
\hline $\mathrm{Cf}_{6}^{6} 0-0-4-8$ & 0,6 abcd & 0,6 abcd & $1,9 \mathrm{~cd}$ & 1,2 & $3,3 \mathrm{ab}$ & $3,8 \mathrm{ab}$ & $3,7 \mathrm{~d}$ & $4,0 \mathrm{~b}$ \\
\hline $\mathrm{Cf}_{6} 0-0-4-9$ & $0,6 \mathrm{ab}$ & $0,8 \mathrm{abc}$ & $2,8 \mathrm{bcd}$ & 3,3 & $6,1 \mathrm{ab}$ & 8,3 a & 7,6 bcd & 15,8 a \\
\hline $\mathrm{Cf}_{6} 0-0-4-13$ & $0,5 \mathrm{bcd}$ & $0,4 \mathrm{bcd}$ & 3,5 abcd & 1,2 & $2,8 \mathrm{ab}$ & $2,7 \mathrm{~b}$ & $13,8 \mathrm{a}$ & $3,3 \mathrm{~b}$ \\
\hline $\mathrm{Cf}_{6} 0-0-5-2$ & 0,6 abcd & 0,4 abcd & $2,5 \mathrm{bcd}$ & 1,3 & $3,3 \mathrm{ab}$ & $3,3 \mathrm{ab}$ & $6,5 \mathrm{~cd}$ & $3,9 \mathrm{~b}$ \\
\hline $\mathrm{Cf}_{6} 0-0-5-4$ & $0,5 \mathrm{bcd}$ & $0,3 \mathrm{~cd}$ & 3,3 abcd & 2,1 & $2,2 \mathrm{ab}$ & $2,3 \mathrm{~b}$ & 7,4 bcd & $9,3 \mathrm{ab}$ \\
\hline $\mathrm{Cf}_{6} 0-0-5-5$ & 0,6 abcd & $0,7 a b c$ & $2,7 \mathrm{bcd}$ & 1,6 & $3,3 \mathrm{ab}$ & $4,3 \mathrm{ab}$ & $6,8 \mathrm{~cd}$ & $4,9 \mathrm{ab}$ \\
\hline $\mathrm{Cf}_{6}^{6} 0-0-5-7$ & $0,4 \mathrm{~d}$ & $0,4 \mathrm{bcd}$ & $2,5 \mathrm{bcd}$ & 1,9 & $2,8 \mathrm{ab}$ & $4,0 \mathrm{ab}$ & $5 \mathrm{~cd}$ & $7,8 \mathrm{ab}$ \\
\hline $\mathrm{Cf}_{6} 0-0-7-1$ & $0,8 \mathrm{a}$ & $0,8 \mathrm{ab}$ & $1,7 \mathrm{~cd}$ & 1,5 & 7,8 a & $4,2 \mathrm{ab}$ & 8,8 abcd & $5,2 \mathrm{ab}$ \\
\hline $\mathrm{Cf}_{6} 0-0-7-2$ & $0,7 \mathrm{ab}$ & $0,8 a b c$ & $2,1 \mathrm{bcd}$ & 1,7 & $4,4 \mathrm{ab}$ & $5,3 \mathrm{ab}$ & $4,6 \mathrm{~cd}$ & $7,8 \mathrm{ab}$ \\
\hline $\mathrm{Cf}_{6} 0-0-7-3$ & $0,7 a b$ & $0,9 \mathrm{a}$ & $1,5 \mathrm{~d}$ & 1,3 & $6,1 \mathrm{ab}$ & $3,5 \mathrm{ab}$ & $6,7 \mathrm{~cd}$ & $4,0 \mathrm{~b}$ \\
\hline $\mathrm{Cf}_{6} 0-0-7-6$ & $0,5 \mathrm{bcd}$ & $0,4 \mathrm{bcd}$ & $4,3 \mathrm{ab}$ & 1,8 & $3,9 \mathrm{ab}$ & $3,3 \mathrm{ab}$ & $13,2 \mathrm{ab}$ & $5,7 \mathrm{ab}$ \\
\hline $\mathrm{Cf}_{6} 0-0-7-7$ & $0,8 \mathrm{a}$ & $0,5 \mathrm{abcd}$ & 3,0 abcd & 2,6 & $4,5 \mathrm{ab}$ & $6,0 \mathrm{ab}$ & 8,8 abcd & $8,2 \mathrm{ab}$ \\
\hline $\mathrm{Cf}_{6}^{0} 0-0-7-8$ & $0,4 \mathrm{~d}$ & $0,2 \mathrm{~d}$ & 3,2 abcd & 2,1 & $1,1 \mathrm{~b}$ & $2,0 \mathrm{~b}$ & $9,5 \mathrm{abcd}$ & $7,0 \mathrm{ab}$ \\
\hline $\mathrm{Cf}_{6} 0-0-7-9$ & $0,5 \mathrm{bcd}$ & 0,4 bcd & $2,5 \mathrm{bcd}$ & 1,8 & $3,9 \mathrm{ab}$ & $3,3 \mathrm{ab}$ & $5,7 \mathrm{~cd}$ & $6,2 \mathrm{ab}$ \\
\hline INIAP-473 & $0,5 \mathrm{bcd}$ & 0,5 abcd & $1,4 \mathrm{~d}$ & 1,2 & $3,4 \mathrm{ab}$ & $4,0 \mathrm{ab}$ & $4,7 \mathrm{~cd}$ & $4,5 \mathrm{ab}$ \\
\hline Promedio & $0,6 \mathrm{~ns}$ & 0,5 & $2,7 \mathrm{~A}$ & $1,8 \mathrm{~B}$ & $3,9 \mathrm{~ns}$. & 4,0 & $7,8 \mathrm{~ns}$. & 6,3 \\
\hline $\mathrm{CV}(\%)$ & 31,07 & 32,02 & 26,32 & 27,07 & 38,79 & 38,62 & 36,44 & 30,44 \\
\hline
\end{tabular}

\footnotetext{
${ }^{1}$ Medias seguidas por la misma letra en la columna no difieren estadísticamente por el test de Tukey al 5\% de probabilidad, entre tanto en la fila no difieren estadísticamente por el test de $\mathrm{T}$ al $5 \%$ de probabilidad.
} 
ocurrida durante noviembre de 2010, que es el $76 \%$ de todo el ciclo del cultivo. Durante ese mes los materiales genéticos atravesaron por el estado fenológico R7, lo que podría haber influenciado el aumento de enfermedad durante ese año.

Esta enfermedad es el principal problema del fréjol en los trópicos húmedos, donde la elevada temperatura y humedad establecen las condiciones favorables para el desarrollo de la enfermedad (Ribeiro-Costa, 2007), no siendo diferente en esta zona del Ecuador, teniendo importancia única, pues es la que predomina sobre las demás enfermedades (Garcés-Fiallos, 2011). Aunque todavía no se ha identificado una línea de fréjol común que tenga alto nivel de resistencia a esta enfermedad en las diferentes regiones geográficas (Beaver et al., 2002), el desarrollo de las líneas promisorias, sanitariamente superiores, pueden ayudar a los agricultores dedicados a la siembra de este cultivo.

El comportamiento del material genético estudiado se diferenció en cada año, debido posiblemente a la diversidad genética de los fitopatógenos causantes de las enfermedades evaluadas. El hongo necrótrofo $R$. solani posee una alta diversidad genética, verificando esta condición en cepas aisladas de fréjol de palo ( $V$. unguiculata) (Sartorato et al., 2006) y fréjol común (Meinhardt et al., 2011). El hongo biotrófico $U$. appendiculatus presenta un comportamiento similar. En el estado de Minas Gerais, Brasil, de 13 aislados colectados y estudiados, siete resultaron razas fisiológicas diferentes, confirmando así la alta variabilidad poblacional de este patógeno (Souza et al., 2003). Inclusive, un mismo patótipo de $U$. appendiculatus puede generar varias respuestas en una misma variedad indicadora (Souza et al., 2005). Esta variabilidad influenciaría en la respuesta diferenciada de cada material en condiciones epifíticas naturales.

El análisis de conglomerados (Figura 1A) realizado para todas las variables sanitarias evidenció cuatro grupos, mostrando las líneas promisorias $\mathrm{Cf}_{6}$ $0-0-1-9, \mathrm{Cf}_{6} 0-0-4-9, \mathrm{Cf}_{6} 0-0-5-2, \mathrm{Cf}_{6} 0-0-5-7, \mathrm{Cf}_{6}$ $0-0-7-1, \mathrm{Cf}_{6} 0-0-7-2, \mathrm{Cf}_{6} 0-0-7-7, \mathrm{Cf}_{6} 0-0-7-8$ y la variedad comercial INIAP-473, como superiores sanitariamente sobre las demás, por obtener valores menores en la suma de todas las variables.

\section{Variables productivas}

Se encontró diferencia estadística únicamente en la variable número de vainas por planta en 2010.
El número de vainas por planta se ubicó entre $10,00\left(\mathrm{Cf}_{6} 0-0-5-5\right)$ y 15,0 vainas $\left(\mathrm{Cf}_{6} 0-0-1-9\right)$ en el 2010, mientras que entre $13,0\left(\mathrm{Cf}_{6} 0-0-3-7\right)$ y 17,3 vainas $\left(\mathrm{Cf}_{6} 0-0-1-12\right)$ en el 2011 . Estos valores son superiores a los encontrados por Shimada et al. (2000) (7,6 y 8,27 vainas) y Abrantes et al. (2011) (10,6 vainas) en genotipos de fréjol de hábito de crecimiento determinado. En los años 2010 y 2011 se encontraron valores entre 12,0 y 14,6 vainas respectivamente (Tabla 6).

Para el peso de campo $\mathrm{kg}$ los valores se ubicaron entre $0,8\left(\mathrm{Cf}_{6} 0-0-5-2\right)$ y $1,4 \mathrm{~kg}\left(\mathrm{Cf}_{6} 0-0-4-8\right.$ y $\left.\mathrm{Cf}_{6} 0-0-5-4\right)$ en 2010 , mientras que entre $1,0\left(\mathrm{Cf}_{6}\right.$ $0-0-7-6$ y Cf $60-0-7-8)$ y $1,4\left(\mathrm{Cf}_{6} 0-0-4-8\right)$ en 2011 (Tabla 6). Así también, el promedio para 2010 y 2011 resultó entre 1,12 y 1,21, respectivamente.

Para el rendimiento de granos $\left(\mathrm{kg} \mathrm{ha}^{-1}\right)$, se encontraron valores entre $1.037,2\left(\mathrm{Cf}_{6} 0-0-5-2\right)$ y $1.554,9\left(\mathrm{Cf}_{6} 0-0-4-9\right)$ en 2010 , y entre $1.800,9\left(\mathrm{Cf}_{6}\right.$ $0-0-7-6)$ y $2.606,7\left(\mathrm{Cf}_{6} 0-0-5-2\right)$ en 2011 (Tabla 6). El potencial productivo de los genotipos en el segundo año de investigación es superior a la media nacional de $350 \mathrm{~kg} \mathrm{ha}^{-1}$ (INEC, 1994), e inclusive superior a los obtenidos por López et al. (2001) en México (597 a 2.013 kg), González-Torres et al. (2008) también en México (1.138 a $2.550 \mathrm{~kg}$ ), Antunes et al. (2007) en el Sur de Brasil durante siete años de investigación (2.110,5 a 2.359,3 kg), Ribeiro et al. (2010) también en el Sur de Brasil (264 a $2.336 \mathrm{~kg}$ ) y Garcés-Fiallos et al. (2012) durante 2010 en Quevedo, Ecuador (610,1 a 1.401,5). La superioridad de estos genotipos con los detallados en la literatura de varios países de América Latina demuestra el potencial productivo de estas líneas promisorias.

El rendimiento promedio del $2010(1.297,3 \mathrm{~kg})$ fue inferior al del $2011(2.118,8)$ (Tabla 6). Las condiciones climáticas durante los dos años fueron similares, a excepción de la heliofanía, mostrando valores entre 115,40 y 170,30 horas luz durante 2010 y 2011, respectivamente, siendo obtenido en este último año 84,30 horas luz en septiembre (Tabla 2). Este comportamiento podría haber sido el causante del aumento del rendimiento, ya que la radiación solar tiene un efecto sobre el fréjol, sobre todo después de la floración, donde el cultivo necesita drenar sus fotoasimilados para la formación de hojas (Santos et al., 2003). Otra limitante que se observó durante el primer año, fue la precipitación, de 21,80 mm de noviembre (estados fenológicos R7 y R8), siendo prácticamente el 75\% 
Tabla 6. Número de vainas por planta, peso de campo $(\mathrm{kg})$ y rendimiento de granos $\left(\mathrm{kg} \mathrm{ha}^{-1}\right)$ en líneas promisorias $\mathrm{F}_{6}$ de fréjol obtenidas en la UTEQ y una variedad comercial, durante la época seca de los años 2010 y 2011. Campo Experimental La María, Quevedo. 2011.

\begin{tabular}{|c|c|c|c|c|c|c|}
\hline \multirow[t]{2}{*}{ Tratamientos } & \multicolumn{2}{|c|}{$\begin{array}{c}\text { Número de vainas } \\
\text { por planta }\end{array}$} & \multicolumn{2}{|c|}{$\begin{array}{c}\text { Peso de campo } \\
(\mathrm{kg})\end{array}$} & \multicolumn{2}{|c|}{$\begin{array}{l}\text { Rendimiento de granos } \\
\qquad\left(\mathrm{kg} \mathrm{ha}^{-1}\right)\end{array}$} \\
\hline & 2010 & 2011 & 2010 & 2011 & 2010 & 2011 \\
\hline $\mathrm{Cf}_{6} 0-0-1-9$ & $15,0 \mathrm{a}^{1}$ & $14,6 \mathrm{~ns}$. & $1,0 \mathrm{~ns}$. & $1,1 \mathrm{~ns}$. & $1217,1 \mathrm{~ns}$. & $1894,8 \mathrm{~ns}$ \\
\hline $\mathrm{Cf}_{6} 0-0-1-12$ & $11,7 \mathrm{ab}$ & 17,3 & 1,2 & 1,2 & 1369,3 & 2185,6 \\
\hline $\mathrm{Cf}_{6} 0-0-3-1$ & $11,3 \mathrm{ab}$ & 13,7 & 1,2 & 1,3 & 1408,7 & 2371,4 \\
\hline $\mathrm{Cf}_{6} 0-0-3-7$ & $11,7 \mathrm{ab}$ & 13,0 & 1,0 & 1,1 & 1138,3 & 1952,1 \\
\hline $\mathrm{Cf}_{6} 0-0-4-8$ & $13,3 \mathrm{ab}$ & 14,2 & 1,4 & 1,4 & 1545,2 & 2475,8 \\
\hline $\mathrm{Cf}_{6} 0-0-4-9$ & $13,7 \mathrm{ab}$ & 13,9 & 1,3 & 1,2 & 1554,9 & 2146,8 \\
\hline $\mathrm{Cf}_{6} 0-0-4-13$ & $13,3 \mathrm{ab}$ & 13,5 & 1,2 & 1,1 & 1347,0 & 1812,7 \\
\hline $\mathrm{Cf}_{6} 0-0-5-2$ & $11,0 \mathrm{ab}$ & 13,1 & 0,8 & 1,5 & 1037,2 & 2606,7 \\
\hline $\mathrm{Cf}_{6}^{0} 0-0-5-4$ & $12,3 \mathrm{ab}$ & 14,2 & 1,4 & 1,3 & 1480,9 & 2304,0 \\
\hline $\mathrm{Cf}_{6} 0-0-5-5$ & $10,0 \mathrm{~b}$ & 14,9 & 1,1 & 1,2 & 1280,2 & 2115,3 \\
\hline $\mathrm{Cf}_{6} 0-0-5-7$ & $12,3 \mathrm{ab}$ & 15,9 & 1,2 & 1,2 & 1421,8 & 2063,8 \\
\hline $\mathrm{Cf}_{6} 0-0-7-1$ & $11,7 \mathrm{ab}$ & 13,8 & 0,9 & 1,1 & 1063,1 & 1824,6 \\
\hline $\mathrm{Cf}_{6}^{0} 0-0-7-2$ & $11,3 a b$ & 16,6 & 1,1 & 1,3 & 1265,3 & 2355,1 \\
\hline $\mathrm{Cf}_{6} 0-0-7-3$ & $12,0 \mathrm{ab}$ & 13,5 & 1,0 & 1,2 & 1199,3 & 2067,0 \\
\hline $\mathrm{Cf}_{6} 0-0-7-6$ & $12,0 \mathrm{ab}$ & 15,2 & 1,0 & 1,0 & 1134,9 & 1800,9 \\
\hline $\mathrm{Cf}_{6}^{0} 0-0-7-7$ & $11,7 \mathrm{ab}$ & 13,9 & 1,2 & 1,3 & 1291,4 & 2255,7 \\
\hline $\mathrm{Cf}_{6} 0-0-7-8$ & $11,7 \mathrm{ab}$ & 15,5 & 1,3 & 1,0 & 1494,3 & 1807,5 \\
\hline $\mathrm{Cf}_{6} 0-0-7-9$ & $11,0 \mathrm{ab}$ & 15,6 & 0,9 & 1,3 & 1082,3 & 2262,2 \\
\hline INIAP-473 & $10,7 \mathrm{ab}$ & 15,5 & 1,1 & 1,1 & 1317,1 & 1955,3 \\
\hline Promedio & $12,0 \mathrm{~ns}$. & 14,6 & 1,12 ns. & 1,21 & 1297,3 B & $2118,8 \mathrm{~A}$ \\
\hline $\mathrm{CV}(\%)$ & 12,38 & 20,64 & 23,23 & 23,58 & 20,39 & 24,00 \\
\hline
\end{tabular}

${ }^{1}$ Medias seguidas por la misma letra en la columna no difieren estadísticamente por el test de Tukey al 5\% de probabilidad del error, entre tanto en la fila no difieren estadísticamente por el test de $\mathrm{T}$ al $5 \%$ de probabilidad del error.

precipitado durante todo el ciclo (Tabla 2). Otro factor que podría haber influenciado drásticamente dichas diferencias en el rendimiento es la fecha de siembra durante 2010 (septiembre) y 2011 (julio). En la zona central del litoral ecuatoriano la época seca empieza en mayo, donde el agricultor aprovecha la humedad remanente del suelo depositado por la precipitación invernal, por lo que siembras cercanas a esta fecha son ideales. La variedad comercial INIAP-473 sembrada el 1 de junio de 2010 obtuvo un rendimiento de granos de 1.648,75 $\mathrm{kg} \mathrm{ha}^{-1}$ (Garcés-Fiallos, 2011), mientras que el mismo material establecido el 20 de septiembre de 2010 obtuvo 1.401,54 kg ha ${ }^{-1}$ (Garcés-Fiallos et al., 2012).
El análisis de conglomerados (Figura 1B) realizado para todas las variables agronómicas y productivas permitió identificar cuatro grupos, mostrando las líneas promisorias $\mathrm{Cf}_{6} 0-0-5-2, \mathrm{Cf}_{6}$ 0-0-7-2, $\mathrm{Cf}_{6}$ 0-0-7-7 y Cf 6 0-0-7-9 como agronómica y productivamente superiores, por obtener valores mayores en la suma de todas las variables.

\section{Conclusiones}

Las líneas promisorias $\mathrm{Cf}_{6} 0-0-5-2, \mathrm{Cf}_{6}$ 0-0-72 y $\mathrm{Cf}_{6}$ 0-0-7-7 resultaron agronómica, sanitaria y productivamente superiores. Durante 2011 se observó una menor AACPEPM y mayor rendimiento de granos $\left(\mathrm{kg} \mathrm{ha}^{-1}\right)$ en comparación con 2010. 


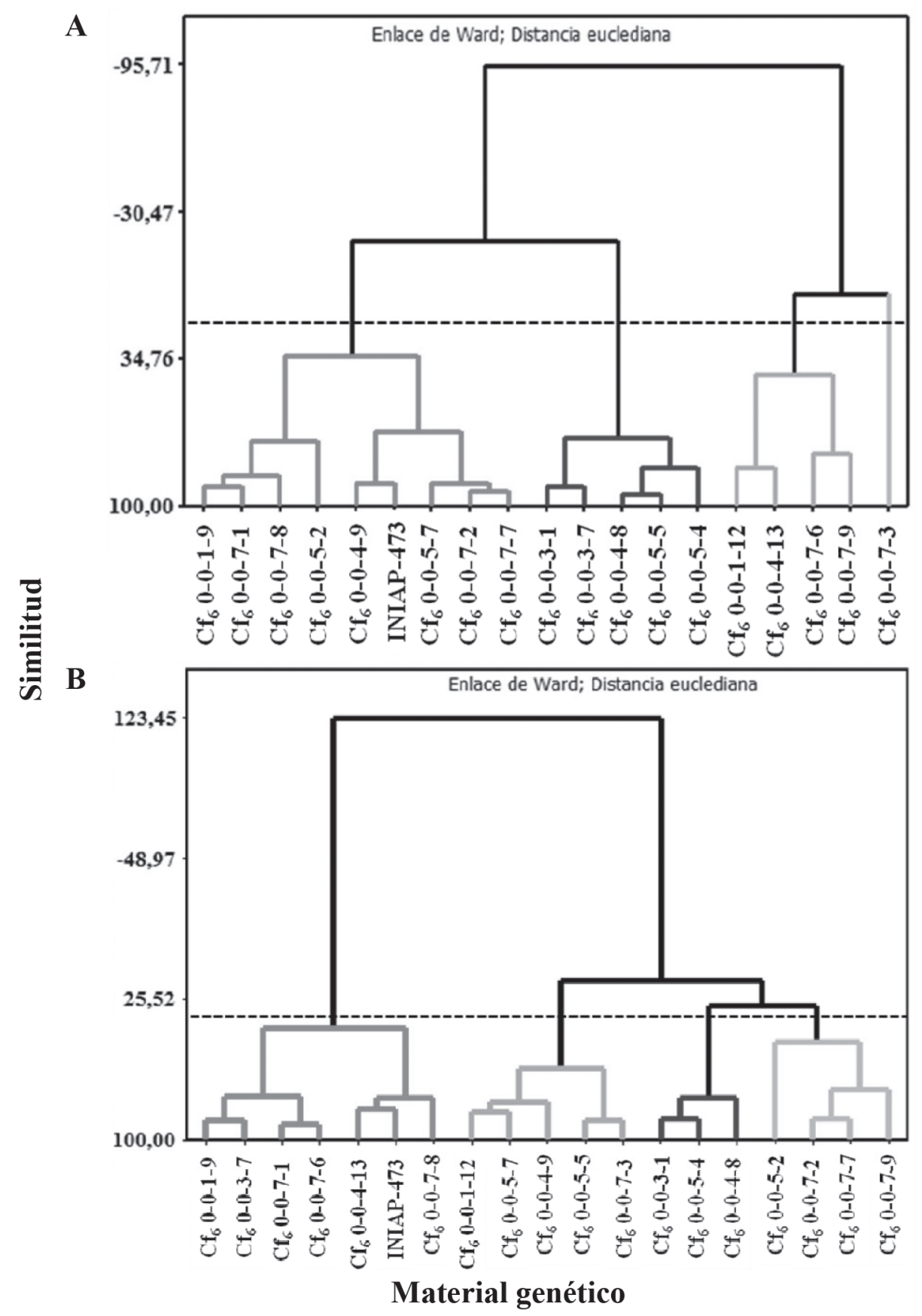

Figura 1. Dendograma de similaridad de las líneas promisorias F6 de fréjol obtenidas en la UTEQ y una variedad comercial para las variables sanitarias (A), así como agronómicas y productivas (B) durante la época seca de los años 2010 y 2011. Campo Experimental La María, Quevedo. 2011. 


\section{Literatura Citada}

Abrantes, F.L.; Eustáquio de Sá, M.; Domingues de Souza, L.C.; Pina da Silva, M.; Simidu, H.M.; Andreotti, M.; Buzetti, S.; Velério-Filho, W.V.; Arruda, N.

2011. Uso de regulador de crescimento em cultivares de feijão de inverno. Pesquisa Agropecuária Tropical, 41(2): 148-154.

Alves-Francelino, F.M.; Gravina, G.de.A.; Coimbra-Manhães, C.M.; Cardoso, P.M.R.; Cordeiro de Araújo, L.

2011. Avaliação de linhagens de feijão-de-vagem para as regiões Norte e Noroeste Fluminense. Ciência Agronômica, 42(2): 554-562.

Antunes, I.F.; Silveira, E.P.; Torres da Silva, E. 2007. BRS Expedito: nova cultivar de feijão de grãos pretos. Pesquisa Agropecuária Brasileira, 42(1): 135-136.

Beaver, J.S.; Godoy, G.; Rosas, J.C.; Steadman, J.

2002. Estrategias para seleccionar frijol común con mayor resistencia a mustia hilachosa. Agronomía Mesoamericana, 13(1): 67-72.

Bianchini, A.; Marrizoni, A.C.; Cameiro, S.N.T.P.G.

2005. Doenças do feijoeiro. In: Manual de Fitopatologia. 4 edición. Kimati, H.; Amorim, L.; Rezende, J.A.M.; Bergamín Filho, A.; Camargo, L.E.A. (Ed.), v. 2. São Paulo-Ceres. pp. 333-349.

Buestán, R.H.

1989. Desarrollo, evaluación y uso de germoplasma de frijol común en el litoral ecuatoriano. In: CIAT. Progreso de la investigación y producción de frijol común (Phaseolus vulgaris L.). Cali-Centro Internacional de Agricultura Tropical (CIAT), pp. 275-277.

Celis-Velázquez, R.; Peña-Valdivia, C.B.; Luna-Cavazos, M.; Aguirre, R.J.R.

2010. Caracterización morfológica de las semillas y consumo de reservas durante la emergencia de plántulas de frijol (Phaseolus vulgaris L.) silvestre y domesticado. Facultad de Agronomía , 27: 61-87.

Costa-Coelho, G.R; Lobo Júnior, M.; Café Filho, A.C.

2012. Epidemiologia da mela e produtividade do feijoeirocomum tratado com fungicidas. Summa Phytopathologica, 38(3): 211-215.

Ernest, E.G.; Falconí-Castillo, E.; Peralta-Idrovo, E.; Kelly, J. 2008. Encuesta a productores para orientar el fitomejoramiento en frijol en Ecuador. Agricultura Mesoamericana, 19(1): 7-18.

Garcés-Fiallos, F.R.

2010. Doenças causadas por vírus na cultura de feijoeiro. Ciencia y Tecnología, 3(2): 1-6.

Garcés-Fiallos, F.R.

2011. Modelo de ponto crítico para estimar danos causados pela mela na cultura do feijoeiro. Ciencia y Tecnología, 4(1): 1-4.

Garcés-Fiallos, F.R.

2013. Cuantificación de enfermedades en líneas promisorias y variedades de fréjol en Quevedo, Ecuador. Biotecnología en el Sector Agropecuario y Agroindustrial, 10(2): 194-205.

Garcés-Fiallos, F.R.; Zabala-Palacios, R.G.; Díaz-Coronel,

T.G.; Vera-Avilés, D.F.

2012. Evaluación agronómica y fitosanitaria de germoplasma de fréjol en el trópico húmedo ecuatoriano. Revista Científica UDO Agrícola, 12(2): 230-240.
Garcés-Fiallos, F.G.; Gamarra-Yánez, H.V.

2014. Intensidade de doenças e produtividade de genótipos promissores de feijão em Quevedo, Equador. Bioscience Journal, 30(5): 1291-1303.

Garcés-Fiallos, F.G.; Gamarra-Yánez, H.V.; Sánchez-Mora, F.; TayHing, C.C.

2013. Modelos integral e de ponto crítico para estimar danos no rendimento e seus componentes pela mela na cultura do feijoeiro. Ciencia y Tecnología, 6(1): 17-22.

Godoy, C.V.; Carneiro, S.M.T.P.G.; Iamauti, M.T.; Pria, M.D.; Amorim, L.; Berger, R.D.; Bergamin Filho, A.

1997. Diagrammatic scales for bean diseases: development and validation. Journal of Plant Diseases and Protection, 104: 336-345.

González-Torres, G.; Mendoza-Hernández, F.M.; Covarrubias-

Prieto, J.; Morán-Vázquez, N.; Acosta-Gallegos, J.A.

2008. Rendimiento y calidad de semilla de frijol en dos épocas de siembra en la región del Bajío. Agricultura Técnica en México, 34(4): 421-430.

Guamán, J.R.; Andrade, V.C.; Álava, A.J.

2003. Variedades mejoradas de fréjol arbustivo para el litoral ecuatoriano. Guayaquil-INIAP Boliche, pp. 20. (Boletín divulgativo).

Hall, R.

1994. Compendium of bean diseases. 2nd. ed. St. Paul-APS, pp. 73.

INEC.

1994. El rendimiento para el fréjol seco. Disponible en: <http:// www.preduza.org/le1_3.htm>. Consultado: 23/08/2010.

Iriti, M.; Faoro, F.

2003. Benzothiadiazole (BTH) induces cell-death independent resistance in Phaseolus vulgaris against Uromyces appendiculatus. Journal of Phytopathology, 151: 171-180.

Lépiz, R.; Minchala, L.; Villacis, M.

1995. Desarrollo de germoplasma de fréjol voluble con resistencia al virus del mosaico común en Azuay y Cañar. Revista INIAP, 5: 20-21.

López, E.; Ugalde, F.J.; Contreras, R.; Barradas, A.

2001. Producción artesanal de semilla de frijol en Veracruz, México. Agronomía Mesoamericana, 12(1): 9-14.

López, E.; Tosquy, O.H.; Villar, B.; Becerra, E.N.; Ugalde, J.F. 2003. Adaptación, resistencia múltiple a enfermedades y tolerancia a suelos ácidos en genotipos de frijol. Agronomía Mesoamericana, 14(2): 151-155.

Meinhardt, L.W.; Wulff, N.A.; Bellato, C.M.; Tsai, S.M.

2002. Genetic analyses of Rhizoctonia solani isolates from Phaseolus vulgaris grown in the Atlantic Rainforest Region of São Paulo, Brazil. Fitopatologia Brasileira, 27: 259-267.

Nechet, K.L.; Halfeld-Vieira, B.A.

2007. Reação de cultivares de feijão-caupi à mela (Rhizoctonia solani) em Roraima. Fitopatologia Brasileira, 32: 424-428.

Ribeiro, N.D.; Cargnelutti Filho, A.; Poersch, N.L.; Rosa, D.P. 2010. Critério de seleção indireta para a produtividade de grãos em feijão. Ciência Rural, 40(4): 986-989.

Rodríguez, E.; Lorenzo, L.; Acosta, M.; González, F.; Mora, B.; Godoy, G.

1999. Manejo de la mustia hilachosa (Thanatephorus cucumeris (Frank)) en el cultivo del frijol común (Phaseolus vulgaris L.). Agronomía Mesoamericana, 10(1): 99-108. 
Ryan, T.A.; Joiner, B.L.; Ryan, B.F.

2005. Encyclopedia of Statistical Sciences. MINITAB ${ }^{\mathrm{TM}}$. Brooks/Cole-Thomson Learning. 5 edition. pp. 505. 2005. Santos, J.B.dos.; Procópio, S.de.O.; Silva, A.A.da.; Costa, L.C. 2003. Captação e aproveitamento da radiação solar pelas culturas da soja e do feijão e por plantas daninhas. Bragantia, 62(1): $147-153$

Sartorato, A.; Nechet, K.L.; Halfed-Vieira, B.A

2006. Diversidade genética de isolados de Rhizoctonia solani coletados em feijão-caupi no Estado de Roraima. Fitopatologia Brasileira, 31: 297-301.

Shimada, M.M.; Arf, O.; Sá, M.E. de

2000. Componentes do rendimento e desenvolvimento do feijoeiro de porte ereto sob diferentes densidades populacionais. Bragantia, 59(2): 181-187.

Silva, F. de A.S.; Azevedo, C.A.V. de

2002. Versão do programa computacional Assistat para o sistema operacional Windows. Revista Brasileira de Produtos Agroindustriais, 4(1): 71-78.
Souza, T.L.P.O.; Ragagnin, V.A.; Sanglarg, D.A.; Moreira, M.A.; Barros, E.G.

2003. Classification of Uromyces appendiculatus physiological races from Minas Gerais, Brazil, using the new binary system. Annual report of the bean improvement cooperative, 48: 158-161.

Souza, T.L.P.O.; Alzate-Marin, A.L.; Moreira, M.A.; Barros, E.G. 2005. Análise comparativa da variabilidade patogênica de Uromyces appendiculatus em algumas regiões brasileiras. Fitopatologia Brasileira, 30: 143-149.

Vargas-Vázquez, M.L.P.; Muruaga-Martínez, J.S.; Pérez-Herrera, P.; Gill-Langarica, H.R.; Esquivel-Esquivel, G.; Martínez-Damián, M.A.; Rosales-Serna, R.; Mayek-Pérez, N.

2008. Caracterización morfoagronómica de la colección núcleo de la forma cultivada de frijol común del INIFAP. Agrociencia, 42: 787-797. 